\title{
Changes in Biomarkers Associated with Living Kidney Donation
}

\author{
Yonghong Huan $^{\mathrm{a}}$ Shiv Kapoor $^{\mathrm{b}}$ Stephanie DeLoach $^{\mathrm{d}}$ Elizabeth Ommen ${ }^{\mathrm{e}}$ \\ Kevin Meyers ${ }^{c}$ Raymond R. Townsend ${ }^{a}$ \\ ${ }^{a}$ Department of Medicine, ${ }^{b}$ Clinical and Translational Research Center and ${ }^{c}$ Department of Pediatrics, \\ University of Pennsylvania, and ${ }^{d}$ Department of Medicine, Thomas Jefferson University, Philadelphia, Pa., and \\ e Department of Medicine, Mount Sinai School of Medicine, New York, N.Y., USA
}

\section{Key Words}

Biomarkers · Cardiovascular disease · Transplantation ·

Risk factors

\begin{abstract}
Living donor kidneys have been associated with better graft and overall survival in kidney transplant recipients. Although a living kidney donation is generally considered safe in carefully selected living donors, concerns of possible adverse effects related to kidney donation remain, especially in younger and high-risk donors. In this study, we examined the changes in a panel of traditional and novel serum biomarkers linked with cardiovascular conditions in a cohort of 34 healthy living kidney donors with a mean age \pm SD of $40 \pm$ 10 years and estimated predonation glomerular filtration rate (GFR) of $86 \pm 10 \mathrm{ml} / \mathrm{min} / 1.73 \mathrm{~m}^{2}$. At 6 months after donation, there were no significant changes in the clinical parameters including body mass index and blood pressure despite a significant decline in the mean estimated GFR to 60 $\mathrm{ml} / \mathrm{min} / 1.73 \mathrm{~m}^{2}$. Among the panel of markers, the levels of symmetric dimethylarginine and fibroblast growth factor 23 increased significantly compared to baseline, suggesting that living kidney donation may result in changes in biomarkers that are associated with cardiovascular risk in other cohorts.

Copyright $\odot 2013$ S. Karger AG, Basel
\end{abstract}

(C) 2013 S. Karger AG, Basel

0250-8095/13/0383-0212\$38.00/0

\section{Introduction}

Kidney transplant remains a preferred treatment option for many patients with end-stage renal disease because of its superior survival compared to dialysis [1]. The waiting time for a deceased donor kidney transplant has increased significantly due to the growing number of patients awaiting transplant, while the supply of deceased donor kidneys has remained limited [2]. In addition to better graft survival compared to deceased donor kidney [3], living kidney donation increases the supply of donor kidneys and reduces the waiting time for kidney transplant recipient. Although living kidney donation is generally considered safe with low cardiovascular disease (CVD) risk in carefully selected donors $[4,5]$, concerns remain especially in younger and higher-risk donors, including ethnic minorities $[6,7]$. The risk of CVD is greater when living kidney donors develop comorbidities like hypertension or diabetes after the donation. The current mandatory follow-up of living kidney donors after donation is only for 2 years with monitoring of blood pressure and urinalysis (http://optn.transplant. hrsa.gov/PoliciesandBylaws2/policies/pdfs/policy_172. pdf). Living kidney donors are known to have modest reduction in glomerular filtration rate (GFR) and some studies suggest an increase in microalbuminuria after

\section{KARGER}

E-Mail karger@karger.com

www.karger.com/ajn
Raymond R. Townsend, MD

University of Pennsylvania

122 Founders Building, 3400 Spruce Street

Philadelphia, PA 19104 (USA)

E-Mail townsend@exchange.upenn.edu 
donation [8]. With long-term follow-up, living kidney donors have shown loss of circadian blood pressure rhythm on ambulatory blood pressure monitoring despite maintaining a normotensive status [9]. However, when this loss of circadian rhythm occurs has not been precisely established, and our recent data found no significant changes in blood pressure and the blood pressure circadian rhythm at 6 months after donation by ambulatory blood pressure monitoring [10].

It is well established that the CVD risk is linked to traditional serum biomarkers like glucose and cholesterol. Moreover, newer data suggest that novel biomarkers like fibroblast growth factor 23 (FGF-23) are also informative about kidney disease progression and death in patients with chronic kidney disease (CKD) [11, 12]. Other biomarkers such as symmetric dimethylarginine (SDMA) and asymmetric dimethylarginine (ADMA) are increased in CKD and associated with endothelial dysfunction and worse cardiovascular outcome [13]. However, little is known about changes in biomarkers after living kidney donation. Given that the postdonation decline of estimated GFR is on average about $30 \mathrm{ml} / \mathrm{min} / 1.73 \mathrm{~m}^{2}$, it is possible that biomarker concentrations in kidney donors increase to levels comparable to those found in patients with similar levels of kidney function from a parenchymal disease process and that they could contribute to the known increased risks of CVD associated with CKD. In this study, we examined a panel of traditional and novel serum biomarkers before and 6 months following living kidney donation. We specifically chose markers of endothelial function, inflammation, and mineral metabolism for this study.

\section{Methods}

\section{Subjects}

Living kidney donors were recruited from two academic transplant centers: the University of Pennsylvania in Philadelphia and Mount Sinai School of Medicine in New York. A total of 34 living kidney donors (14 from the University of Pennsylvania and 20 from Mount Sinai) had blood samples collected before and at 6 months after donation, and were included in these analyses. All subjects provided informed written consent and the study protocols were approved by the institutional review boards of the University of Pennsylvania and Mount Sinai School of Medicine.

\section{Clinical and Hemodynamic Measures}

For all subjects recruited from the Hospital of University of Pennsylvania, brachial blood pressures were recorded from the right arm in the seated position by the nursing staff in the transplant program using a Dinamap device (GE Healthcare, Milwaukee, Wisc., USA). Six-month follow-up blood pressures were per- formed by the nursing staff in the Clinical and Translational Research Center using a Datascope device (Datascope, Mahwah, N.J., USA) located adjacent to the transplant program offices. Clinical and hemodynamic measurements were obtained in similar fashion using a Welch Allyn oscillometric device at Mount Sinai Medical Center.

Kidney function was determined using the estimated GFR, calculated from the simplified Modification of Diet in Renal Disease (MDRD) equation [14] and the Chronic Kidney Disease Epidemiology Collaboration (CKD-EPI) equation [15] in blood drawn before donation and 6 months after donation.

\section{Assays for Biomarkers}

Fasting blood samples were obtained before and 6 months after donation. The blood samples were immediately placed on ice and centrifuged at 3,000 r.p.m. for $10 \mathrm{~min}$ at $4^{\circ} \mathrm{C}$. The serum was separated and immediately stored at $-70^{\circ} \mathrm{C}$ before analysis.

Arginine, homoarginine ADMA, and SDMA were measured simultaneously by high-performance liquid chromatography with fluorescence detection [16]. Plasma, $0.2 \mathrm{ml}$, was mixed with $0.1 \mathrm{ml}$ of a $40-\mu \mathrm{M}$ solution of the internal standard L-NMMA and $0.8 \mathrm{ml}$ of phosphate-buffered saline. This mixture was applied to Oasis MCX solid-phase extraction columns (Waters, Milford, Mass., USA) for the extraction of basic amino acids. The columns were consecutively washed with $1.0 \mathrm{ml}$ of $100 \mathrm{mM} \mathrm{HCl}$ and $1.0 \mathrm{ml}$ of methanol. Analytes were eluted with $1.0 \mathrm{ml}$ of concentrated ammonia/water/methanol (10/40/50). After evaporation of the solvent under nitrogen, the amino acids were derivatized with an $o$ phthalaldehyde reagent containing 3-mercaptopropionic acid. The derivatives were separated by isocratic reversed-phase chromatography on a Symmetry C18 column $(3.9 \times 150 \mathrm{~mm}, 5-\mu \mathrm{m}$ particle size; Waters). Potassium phosphate buffer (50 mM; pH 6.5) containing $8.7 \%$ acetonitrile was used as the mobile phase at a flow rate of $1.2 \mathrm{ml} / \mathrm{min}$ and a column temperature of $30^{\circ} \mathrm{C}$. Fluorescence detection was performed at excitation and emission wavelengths of 340 and $455 \mathrm{~nm}$, respectively. After elution of the last analyte, strongly retained compounds were quickly eluted by a strong solvent flush with $50 \%$ acetonitrile, resulting in a total analysis time of $25 \mathrm{~min}$. The intra-assay coefficients of variations (CVs) for arginine, ADMA, and SDMA were 3.5, 4.6, and 3.8\%, respectively. The interassay CVs for arginine, ADMA, and SDMA were $4.1,5.7$, and $6.4 \%$, respectively.

FGF-23 was measured by ELISA (second-generation C terminal) using kits from Immutopics (San Clemente, Calif., USA). Intra- and interassay CVs were less than 4.5 and $6.2 \%$, respectively. Inflammatory cytokines, TNF-1 $\alpha$ and IL-6, were measured by ELISA kits from R\&D Systems (Minneapolis, Minn., USA). Intraand interassay CVs were less than 5.9 and $6.8 \%$, respectively. hsCRP was measured using a Roche Analyzer with intra- and interassay CVs that were less than 6.3 and $7.5 \%$, respectively.

\section{Statistics}

Data are presented as means \pm SD. Descriptive statistics were used to characterize subject demographics and clinical parameters. A paired t test was used to evaluate change in hemodynamic and laboratory parameters within subjects over the study time points. Analyses were performed using STATA v11.0 (SAS Institute, Carey, N.C., USA). Pearson's correlation coefficient was used to evaluate relationships between estimated GFR and biomarkers. 
Table 1. Characteristics of study participants

\begin{tabular}{lccc}
\hline Parameter & Baseline & $\begin{array}{l}6 \text { months } \\
\text { after } \\
\text { donation }\end{array}$ & \\
\hline Age, years & $40.2 \pm 10.08$ & - & \\
Male & $17(50)$ & - & \\
BMI, kg/m & & \\
SBP, mm Hg & $26.3 \pm 4.1$ & $26.0 \pm 4.2$ & $\mathrm{NS}$ \\
DBP, mm Hg & $125 \pm 10$ & $115 \pm 8$ & $<0.001$ \\
Serum creatinine, $\mathrm{mg} / \mathrm{dl}$ & $76 \pm 7$ & $74 \pm 6$ & $\mathrm{NS}$ \\
MDRD eGFR, ml/min $/ 1.73 \mathrm{~m}^{2}$ & $0.9 \pm 0.2$ & $1.3 \pm 0.2$ & $<0.001$ \\
CKD-EPI eGFR, $\mathrm{ml} / \mathrm{min} / 1.73 \mathrm{~m}^{2}$ & $96 \pm 10.3$ & $60 \pm 11.7$ & $<0.001$ \\
& 96.3 & $64 \pm 14.2$ & $<0.001$ \\
\hline
\end{tabular}

Values are means \pm SD or $\mathrm{n}(\%) . \mathrm{SBP}=$ Systolic blood pressure; $\mathrm{DBP}=$ diastolic blood pressure .

\section{Results}

Table 1 lists the demographic and clinical information of the cohort. At the time of donation, the mean age was $40 \pm 10$ years. The mean BMI of this cohort was $26.3 \pm 4.1$ before donation and remained unchanged 6 months after donation. Both the mean systolic and diastolic blood pressures were normal in this group before donation and remained normal at 6 months after donation. The mean creatinine level increased from $0.9 \pm 0.2 \mathrm{mg} / \mathrm{dl}$ before donation to $1.3 \pm 0.2$ at 6 months after donation, with an estimated GFR decreasing from $86 \pm 10 \mathrm{ml} / \mathrm{min} / 1.73 \mathrm{~m}^{2}$ before donation to $60 \pm 12$ at 6 months after donation using the MDRD equation. A similar magnitude of reduction in eGFR occurred using the CKD-EPI equation. The demographics of the cohort in table 1 are similar to the 88 subjects screened in the transplant program at the University of Pennsylvania during the time period of the study.

Table 2 summarizes the changes in the panel of biomarkers from baseline to 6 months after donation. Among the markers of endothelial function, SDMA showed a significant increase in its level at 6 months after donation, while ADMA and arginine showed a trend towards increases but failed to reach statistical significance. FGF-23 demonstrated a marginally significant increase at 6 months after donation. The inflammatory markers failed to show significant changes at 6 months after donation.

There was a modest correlation between eGFR and FGF-23 ( $\mathrm{r}=-0.34 ; \mathrm{p}=0.069)$ and a weaker correlation of eGFR with SDMA $(r=-0.24 ; p=0.183)$ before donation. The relationship between eGFR and FGF-23 was similar after donation $(\mathrm{r}=-0.37 ; \mathrm{p}=0.055)$, but the correlation between eGFR and SDMA was weaker $(r=0.12$; $\mathrm{p}=$
Table 2. Levels of biomarkers before the donation and 6 months after the donation

\begin{tabular}{lllr}
\hline Marker & $\begin{array}{l}\text { Before } \\
\text { donation }\end{array}$ & $\begin{array}{l}\text { 6 months after } \\
\text { donation }\end{array}$ & $\mathrm{p}$ \\
\hline ARG, $\mu \mathrm{M}$ & $66.7 \pm 18.8$ & $74.9 \pm 17.5$ & 0.078 \\
$\mathrm{hARG}, \mu \mathrm{M}$ & $2.07 \pm 0.7$ & $2.02 \pm 0.6$ & 0.761 \\
$\mathrm{ADMA}, \mu \mathrm{M}$ & $0.33 \pm 0.07$ & $0.36 \pm 0.08$ & 0.064 \\
SDMA, $\mu \mathrm{M}$ & $0.47 \pm 0.11$ & $0.62 \pm 0.15$ & $<0.001$ \\
FGF-23, RU/ml & $54.0 \pm 27.9$ & $70.0 \pm 32.9$ & 0.041 \\
TNF-1a, pg/ml & $2.03 \pm 1.53$ & $2.60 \pm 1.48$ & 0.143 \\
IL-6, pg/ml & $1.59 \pm 0.97$ & $1.79 \pm 1.30$ & 0.501 \\
hsCRP, mg/l & $3.89 \pm 6.38$ & $2.14 \pm 2.60$ & 0.367 \\
\hline
\end{tabular}

Values are means $\pm \mathrm{SD} . \mathrm{ARG}=$ Arginine; $\mathrm{hARG}=$ homoargi nine.

0.510). The correlation of other biomarkers with eGFR before or after donation was not significant ( $p$ value generally $>0.2$ for all pairwise correlations).

\section{Discussion}

Our cohort of 34 relatively young living kidney donors with a mean age of 40 years and a BMI in the overweight range had an expected decline in estimated GFR $(26 \mathrm{ml} /$ $\min / 1.73 \mathrm{~m}^{2}$ on average) at 6 months after donation. Markers of endothelial function and bone metabolism demonstrated significant changes related to the decline in GFR, but the inflammatory markers showed no significant changes. While the mean diastolic blood pressure remained unchanged, the mean systolic blood pressure was significantly lower at 6 months after donation as we reported previously [10]. The changes in estimated GFR we observed are similar to those recently reported by Kasiske et al. [17] 6 months after donation.

ADMA is an endogenous inhibitor of endothelial nitric oxide synthase and has been implicated in the pathogenesis of endothelial dysfunction and atherosclerosis due to reduced production and availability of endothelium-derived nitric oxide. Elevated ADMA levels predict worse CVD outcomes in patients with hypertension, diabetes [18], proteinuria $[19,20]$, CKD [20, 21], stroke [22], peripheral vascular disease [23], ischemic heart disease $[18,20,24]$, and congestive heart failure [25-27]. In a cohort of 24 healthy living kidney donors, Kielstein et al. [28] showed that ADMA levels decreased transiently after donation followed by significant elevation at 7 days after donation. We observed a trend towards higher ADMA 
levels at 6 months after donation compared to baseline, which suggests a predisposition to endothelial dysfunction after donation.

SDMA, a structural isomer of ADMA eliminated by renal excretion, inhibits endothelial nitric oxide production by limiting the availability of L-arginine, the main substrate for nitric oxide synthase. In longitudinal studies, SDMA levels correlate with poorer CVD outcomes including myocardial infarction, stroke, and death [2931]. Recent data also suggests that SDMA is involved in inflammation by inducing the production of mediators including IL-6, TNF- $\alpha$, and NF- $\kappa \mathrm{B}$ [32]. In a recent study of 24 healthy living kidney donors, Kielstein et al. [33] showed that SDMA increased significantly within $6 \mathrm{~h}$ after unilateral nephrectomy and remained persistently elevated up to 7 days afterwards. We observed that SDMA was significantly elevated 6 months after donation, suggesting that the effects of living kidney donation may persist chronically, though we did not see an increase in systemic markers of inflammation. In our subjects, although both IL-6 and TNF- $a$ were numerically higher after donation, they were not statistically significantly higher, which is likely because of the small numbers and variability in their measurement.

Homoarginine is a cationic amino acid derived from lysine. It may increase the nitric oxide availability and enhance endothelial function by serving as a precursor of nitric oxide, increasing the intracellular concentration of L-arginine. It inhibits the enzyme arginase which competes with nitric oxide synthase for the key substrate Larginine. Data from the Ludwigshafen Risk and Cardiovascular Health (LURIC) Study and Diet Deutsche Diabetes Dialysis (4D) Study indicate that homoarginine levels are independently associated with cardiovascular and all-cause mortality in patients referred for coronary angiography and in patients undergoing hemodialysis [34]. Although we observed a numerical decrease in homoarginine levels at 6 months after donation, the changes were not statistically significant.

FGF-23 regulates phosphorous metabolism by increasing phosphate excretion. Serum levels of FGF-23 increase progressively as kidney function deteriorates. Elevated FGF-23 is an independent risk factor for mortality in both incident and prevalent dialysis patients [35, 36], and a predictor of more rapid progression of renal function in early stages of both nondiabetic and diabetic CKD $[37,38]$. Recently published data from the large multicenter prospective observational Chronic Renal Insufficiency Cohort (CRIC) study observed that FGF-23 elevations predicted mortality across the entire spectrum of
$\mathrm{CKD}$, and predicted end-stage renal disease in patients with early-stage CKD with estimated GFR above $30 \mathrm{ml} /$ $\mathrm{min} / 1.73 \mathrm{~m}^{2}$ [39]. Data from both animal and clinic studies demonstrated that FGF-23 elevation plays a causal role in the pathogenesis of left ventricular hypertrophy [40]. In our study, we observed increases in FGF-23 levels at 6 months after donation, consistent with the modest reduction in GFR. In a recent report comparing kidney donors 5 years after donation with age-matched controls, Young et al. [41] observed FGF-23 levels that were 30\% higher, which is similar to the change we observed in our donors at 6 months. We did not measure parathyroid hormone concentrations in our study, but parathyroid hormone was higher in donors compared with either predonation values in the donors or control subjects in the reports by Kasiske et al. [17] and Young et al. [41].

In a cohort of 24 healthy living kidney donors, Kielstein et al. [28] found that inflammatory mediators including CRP and IL-6 increased acutely after donation followed by a progressive decline, and the levels remained significantly elevated at 7 days after donation. In our cohort, however, we did not observe significant changes in inflammatory markers 6 months after donation. In the study by Kasiske et al. [17], CRP was slightly increased at 6 months after donation in donors, with a similar change in CRP also noted in the controls.

Our study has several limitations. The sample size is modest, follow-up was limited to a single visit at 6 months, and the study was not designed to determine whether there are clinical consequences to the changes in biomarkers we observed in our cohort. A larger study and a CKD control group with which to compare both the biomarker concentrations and the course of kidney function over time would be the ideal next step in this area.

In summary, we observed that living kidney donation, commonly accepted as a relatively safe procedure has virtually no short-term clinical adverse consequences on common clinical factors such as blood pressure and BMI. The observed reduction in estimated GFR in our cohort is comparable to other studies of similar living kidney donor populations. We observed significant changes in several biomarkers which are associated with adverse effects in endothelial function and bone metabolism at 6 months after living kidney donation, though we lack longitudinal data with which to frame the clinical consequence of these changes. Given the pressure to expand living kidney donation, our findings could be important in clarifying the role of representative biomarkers like SDMA and FGF-23 in patients with parenchymal kidney disease concerning their effects in patients with a surgical reduction in kidney 
function who are otherwise relatively healthy, and could also argue for considering longer follow-up of the living kidney donor population.

\section{Acknowledgments}

This work was supported in part by a Clinical Research Program award from the American Heart Association, Macy Foundation grant, NIH/NIDDK grant (No. 5K23DK076619), and NIH/
NCRR grant (No. UL1RR024134). The content is the responsibility of the authors alone and does not necessarily reflect the views or policies of the AHA, Macy Foundation, or National Institutes of Health.

\section{Disclosure Statement}

None to declare.

\section{References}

-1 Port FK, Wolfe RA, Mauger EA, Berling DP, Jiang K: Comparison of survival probabilities for dialysis patients vs cadaveric renal transplant recipients. JAMA 1993;270:1339-1343.

-2 Sanfilippo FP, Vaughn WK, Peters TG, Shield CF III, Adams PL, Lorber MI, Williams GM: Factors affecting the waiting time of cadaveric kidney transplant candidates in the United States. JAMA 1992;267:247-252.

-3 Terasaki PI, Cecka JM, Gjertson DW, Takemoto S: High survival rates of kidney transplants from spousal and living unrelated donors. N Engl J Med 1995;333:333-336.

-4 Ibrahim HN, Foley R, Tan L, Rogers T, Bailey RF, Guo H, Gross CR, Matas AJ: Long-term consequences of kidney donation. N Engl J Med 2009;360:459-469.

$\checkmark 5$ Segev DL, Muzaale AD, Caffo BS, Mehta SH, Singer AL, Taranto SE, McBride MA, Montgomery RA: Perioperative mortality and long-term survival following live kidney donation. JAMA 2010;303:959-966.

-6 Lentine KL, Schnitzler MA, Xiao H, Saab G, Salvalaggio PR, Axelrod D, Davis CL, Abbott KC, Brennan DC: Racial variation in medical outcomes among living kidney donors. N Engl J Med 2010;363:724-732.

7 Lin J, Kramer H, Chandraker AK: Mortality among living kidney donors and comparison populations. N Engl J Med 2010;363:797-798.

$>8$ Garg AX, Muirhead N, Knoll G, Yang RC, Prasad GV, Thiessen-Philbrook H, RosasArellano MP, Housawi A, Boudville N: Proteinuria and reduced kidney function in living kidney donors: a systematic review, metaanalysis, and meta-regression. Kidney Int 2006;70:1801-1810.

9 Goto N, Uchida K, Morozumi K, Ueki T, Matsuoka S, Katayama A, Haba T, Tominaga Y, Fukuda M, Nakao A, Kimura G: Circadian blood pressure rhythm is disturbed by nephrectomy. Hypertens Res 2005;28:301-306.

10 Deloach SS, Meyers KE, Townsend RR: Living donor kidney donation: another form of white coat effect. Am J Nephrol 2012;35:7579.

-11 Ix JH, Katz R, Kestenbaum BR, de Boer IH, Chonchol M, Mukamal KJ, Rifkin D, Siscovick DS, Sarnak MJ, Shlipak MG: Fibroblast growth factor-23 and death, heart failure, and cardiovascular events in community-living individuals: CHS (Cardiovascular Health Study). J Am Coll Cardiol 2012;60:200-207.

12 Kendrick J, Cheung AK, Kaufman JS, Greene T, Roberts WL, Smits G, Chonchol M: FGF23 associates with death, cardiovascular events, and initiation of chronic dialysis. J Am Soc Nephrol 2011;22:1913-1922.

13 Kielstein JT, Fliser D, Veldink H: Asymmetric dimethylarginine and symmetric dimethylarginine: axis of evil or useful alliance? Semin Dial 2009;22:346-350.

14 Levey AS, Stevens LA, Schmid CH, Zhang YL, Castro AF III, Feldman HI, Kusek JW, Eggers P, Van Lente F, Greene T, Coresh J: A new equation to estimate glomerular filtration rate. Ann Intern Med 2009;150:604-612.

15 Stevens LA, Li S, Kurella TM, Chen SC, Vassalotti JA, Norris KC, Whaley-Connell AT, Bakris GL, McCullough PA: Comparison of the CKD Epidemiology Collaboration (CKDEPI) and Modification of Diet in Renal Disease (MDRD) study equations: risk factors for and complications of CKD and mortality in the Kidney Early Evaluation Program (KEEP). Am J Kidney Dis 2011;57:S9-S16.

16 Teerlink T, Nijveldt RJ, de Jong S, van Leeuwen PA: Determination of arginine, asymmetric dimethylarginine, and symmetric dimethylarginine in human plasma and other biological samples by high-performance liquid chromatography. Anal Biochem 2002; 303:131-137.

17 Kasiske BL, Anderson-Haag T, Ibrahim HN, Pesavento TE, Weir MR, Nogueira JM, Cosio FG, Kraus ES, Rabb HH, Kalil RS, Posselt AA, Kimmel PL, Steffes MW: A prospective controlled study of kidney donors: baseline and 6-month follow-up. Am J Kidney Dis 2013, E-pub ahead of print.

18 Cavusoglu E, Ruwende C, Chopra V, Poludasu S, Yanamadala S, Frishman WH, Eng C, Pinsky DJ, Marmur JD: Relation of baseline plasma ADMA levels to cardiovascular morbidity and mortality at two years in men with diabetes mellitus referred for coronary angiography. Atherosclerosis 2010;210:226231.
19 Tsioufis C, Dimitriadis K, Andrikou E, Thomopoulos C, Tsiachris D, Stefanadi E, Mihas C, Miliou A, Papademetriou V, Stefanadis C: ADMA, C-reactive protein, and albuminuria in untreated essential hypertension: a cross-sectional study. Am J Kidney Dis 2010;55:1050-1059.

20 Lu TM, Chung MY, Lin CC, Hsu CP, Lin SJ: Asymmetric dimethylarginine and clinical outcomes in chronic kidney disease. Clin J Am Soc Nephrol 2011;6:1566-1572.

21 Ravani P, Tripepi G, Malberti F, Testa S, Mallamaci F, Zoccali C: Asymmetrical dimethylarginine predicts progression to dialysis and death in patients with chronic kidney disease: a competing risks modeling approach. J Am Soc Nephrol 2005;16:2449-2455.

22 Worthmann H, Chen S, Martens-Lobenhoffer J, Li N, Deb M, Tryc AB, Goldbecker A, Dong Q, Kielstein JT, Bode-Boger SM, Weissenborn K: High plasma dimethylarginine levels are associated with adverse clinical outcome after stroke. J Atheroscler Thromb 2011;18:753-761

23 Mittermayer F, Krzyzanowska K, Exner M, Mlekusch W, Amighi J, Sabeti S, Minar E, Muller M, Wolzt M, Schillinger M: Asymmetric dimethylarginine predicts major adverse cardiovascular events in patients with advanced peripheral artery disease. Arterioscler Thromb Vasc Biol 2006;26:2536-2540.

24 Krempl TK, Maas R, Sydow K, Meinertz T, Boger RH, Kahler J: Elevation of asymmetric dimethylarginine in patients with unstable angina and recurrent cardiovascular events. Eur Heart J 2005;26:1846-1851.

25 Duckelmann C, Mittermayer F, Haider DG, Altenberger J, Eichinger J, Wolzt M: Asymmetric dimethylarginine enhances cardiovascular risk prediction in patients with chronic heart failure. Arterioscler Thromb Vasc Biol 2007;27:2037-2042.

26 Wilson Tang WH, Tong W, Shrestha K, Wang Z, Levison BS, Delfraino B, Hu B, Troughton RW, Klein AL, Hazen SL: Differential effects of arginine methylation on diastolic dysfunction and disease progression in patients with chronic systolic heart failure. Eur Heart J 2008;29:2506-2513. 
-27 Zairis MN, Patsourakos NG, Tsiaousis GZ, Theodossis GA, Melidonis A, Makrygiannis SS, Velissaris D, Batika PC, Argyrakis KS, Tzerefos SP, Prekates AA, Foussas SG: Plasma asymmetric dimethylarginine and mortality in patients with acute decompensation of chronic heart failure. Heart 2012;98:860-864.

28 Kielstein JT, Veldink H, Martens-Lobenhoffer J, Haller H, Perthel R, Lovric S, Lichtinghagen R, Kliem V, Bode-Boger SM: Unilateral nephrectomy causes an abrupt increase in inflammatory mediators and a simultaneous decrease in plasma ADMA: a study in living kidney donors. Am J Physiol Renal Physiol 2011;301:F1042-F1046.

-29 Kielstein JT, Salpeter SR, Bode-Boeger SM, Cooke JP, Fliser D: Symmetric dimethylarginine (SDMA) as endogenous marker of renal function - a meta-analysis. Nephrol Dial Transplant 2006;21:2446-2451.

30 Schulze F, Carter AM, Schwedhelm E, Ajjan R, Maas R, von Holten RA, Atzler D, Grant PJ, Boger RH: Symmetric dimethylarginine predicts all-cause mortality following ischemic stroke. Atherosclerosis 2010;208:518-523.

- 31 Kiechl S, Lee T, Santer P, Thompson G, Tsimikas S, Egger G, Holt DW, Willeit J, Xu Q, Mayr M: Asymmetric and symmetric dimethylarginines are of similar predictive value for cardiovascular risk in the general population. Atherosclerosis 2009;205:261-265.
2 Schepers E, Barreto DV, Liabeuf S, Glorieux G, Eloot S, Barreto FC, Massy Z, Vanholder R: Symmetric dimethylarginine as a proinflammatory agent in chronic kidney disease. Clin J Am Soc Nephrol 2011;6:2374-2383.

33 Kielstein JT, Veldink H, Martens-Lobenhoffer J, Haller H, Burg M, Lorenzen JM, Lichtinghagen R, Bode-Boger SM, Kliem V: SDMA is an early marker of change in GFR after living-related kidney donation. Nephrol Dial Transplant 2011;26:324-328.

34 Marz W, Meinitzer A, Drechsler C, Pilz S, Krane V, Kleber ME, Fischer J, Winkelmann BR, Bohm BO, Ritz E, Wanner C: Homoarginine, cardiovascular risk, and mortality. Circulation 2010;122:967-975.

35 Gutierrez OM, Mannstadt M, Isakova T, Rauh-Hain JA, Tamez H, Shah A, Smith K, Lee $\mathrm{H}$, Thadhani R, Juppner H, Wolf M: Fibroblast growth factor 23 and mortality among patients undergoing hemodialysis. $\mathrm{N}$ Engl J Med 2008;359:584-592.

36 Jean G, Terrat JC, Vanel T, Hurot JM, Lorriaux C, Mayor B, Chazot C: High levels of serum fibroblast growth factor (FGF)-23 are associated with increased mortality in long haemodialysis patients. Nephrol Dial Transplant 2009;24:2792-2796.

37 Fliser D, Kollerits B, Neyer U, Ankerst DP, Lhotta K, Lingenhel A, Ritz E, Kronenberg F, Kuen E, Konig P, Kraatz G, Mann JF, Muller GA, Kohler H, Riegler P: Fibroblast growth factor 23 (FGF23) predicts progression of chronic kidney disease: the Mild to Moderate Kidney Disease (MMKD) Study. J Am Soc Nephrol 2007;18:2600-2608.
38 Titan SM, Zatz R, Graciolli FG, dos Reis LM, Barros RT, Jorgetti V, Moyses RM: FGF-23 as a predictor of renal outcome in diabetic nephropathy. Clin J Am Soc Nephrol 2011;6: 241-247.

39 Isakova $\mathrm{T}, \mathrm{Xie} \mathrm{H}$, Yang W, Xie D, Anderson AH, Scialla J, Wahl P, Gutierrez OM, Steigerwalt S, He J, Schwartz S, Lo J, Ojo A, Sondheimer J, Hsu CY, Lash J, Leonard M, Kusek JW, Feldman HI, Wolf M: Fibroblast growth factor 23 and risks of mortality and end-stage renal disease in patients with chronic kidney disease. JAMA 2011;305:2432-2439.

40 Faul C, Amaral AP, Oskouei B, Hu MC, Sloan A, Isakova T, Gutierrez OM, Aguillon-Prada R, Lincoln J, Hare JM, Mundel P, Morales A, Scialla J, Fischer M, Soliman EZ, Chen J, Go AS, Rosas SE, Nessel L, Townsend RR, Feldman HI, St John SM, Ojo A, Gadegbeku C, Di Marco GS, Reuter S, Kentrup D, Tiemann K, Brand M, Hill JA, Moe OW, Kuro O, Kusek JW, Keane MG, Wolf M: FGF23 induces left ventricular hypertrophy. J Clin Invest 2011; 121:4393-4408.

41 Young A, Hodsman AB, Boudville N, Geddes C, Gill J, Goltzman D, Jassal SV, Klarenbach S, Knoll G, Muirhead N, Prasad GV, Treleaven D, Garg AX: Bone and mineral metabolism and fibroblast growth factor 23 levels after kidney donation. Am J Kidney Dis 2012;59: 761-769. 